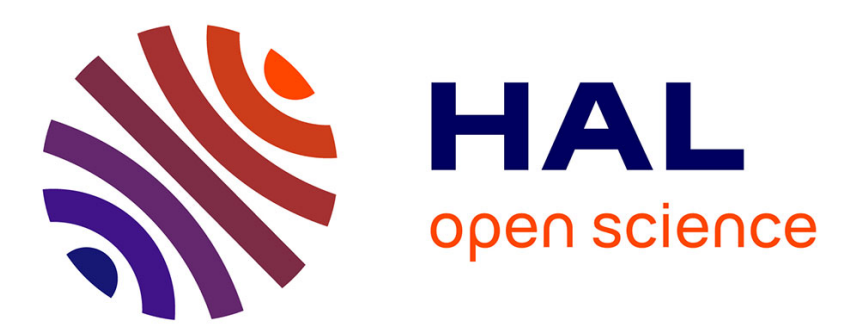

\title{
Emergence of cortistatin as a new immunomodulatory factor with therapeutic potential in immune disorders Elena Gonzalez-Rey, Mzario Delgado
}

\section{To cite this version:}

Elena Gonzalez-Rey, Mzario Delgado. Emergence of cortistatin as a new immunomodulatory factor with therapeutic potential in immune disorders. Molecular and Cellular Endocrinology, 2008, 286 (1-2), pp.135. 10.1016/j.mce.2007.08.001 . hal-00531944

\section{HAL Id: hal-00531944 https://hal.science/hal-00531944}

Submitted on 4 Nov 2010

HAL is a multi-disciplinary open access archive for the deposit and dissemination of scientific research documents, whether they are published or not. The documents may come from teaching and research institutions in France or abroad, or from public or private research centers.
L'archive ouverte pluridisciplinaire HAL, est destinée au dépôt et à la diffusion de documents scientifiques de niveau recherche, publiés ou non, émanant des établissements d'enseignement et de recherche français ou étrangers, des laboratoires publics ou privés. 


\section{Accepted Manuscript}

Title: Emergence of cortistatin as a new immunomodulatory factor with therapeutic potential in immune disorders

Authors: Elena Gonzalez-Rey, Mzario Delgado

PII: S0303-7207(07)00285-7

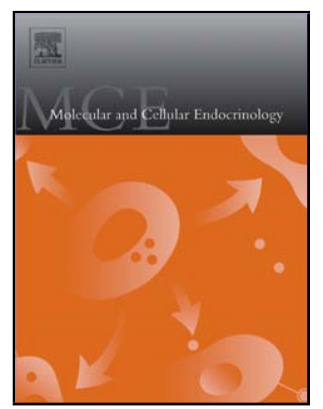

DOI: doi:10.1016/j.mce.2007.08.001

Reference: MCE 6689

To appear in: Molecular and Cellular Endocrinology

Received date:

30-5-2007

Revised date:

$1-8-2007$

Accepted date:

$1-8-2007$

Please cite this article as: Gonzalez-Rey, E., Delgado, M., Emergence of cortistatin as a new immunomodulatory factor with therapeutic potential in immune disorders, Molecular and Cellular Endocrinology (2007), doi:10.1016/j.mce.2007.08.001

This is a PDF file of an unedited manuscript that has been accepted for publication. As a service to our customers we are providing this early version of the manuscript. The manuscript will undergo copyediting, typesetting, and review of the resulting proof before it is published in its final form. Please note that during the production process errors may be discovered which could affect the content, and all legal disclaimers that apply to the journal pertain. 


\title{
EMERGENCE OF CORTISTATIN AS A NEW IMMUNOMODULATORY FACTOR WITH THERAPEUTIC POTENTIAL IN IMMUNE DISORDERS ELENA GONZALEZ-REY* AND MARIO DELGADO ${ }^{\dagger}$
}

\begin{abstract}
*Departamento de Bioquimica Medica y Biologia Molecular, Universidad de Sevilla, Sevilla 41009, Spain; and 'Instituto de Parasitologia y Biomedicina, Consejo Superior de Investigaciones Cientificas, Granada 18100, Spain.
\end{abstract}

Corresponding Author: Mario Delgado, Instituto de Parasitologia y Biomedicina, CSIC, Avd. Conocimiento, PT Ciencias de la Salud, Granada 18100, Spain. Phone: 34-958181665. Fax: 34-958-181632. email: mdelgado@ipb.csic.es 


\begin{abstract}
Identification of the factors that regulate the immune tolerance and control the appearance of exacerbated inflammatory conditions is crucial for the development of new therapies of autoimmune diseases. Some neuropeptides and hormones have emerged as endogenous agents that participate in the regulation of the processes that ensure self-tolerance. Among them, cortistatin, an endogenous cyclic neuropeptide relative of somatostatin, has recently shown therapeutic potential for a variety of immune disorders. Here we examine the latest research findings, which indicate that cortistatin participates in maintaining immune tolerance in two distinct ways: by regulating the balance between pro-inflammatory and antiinflammatory factors, and by inducing the emergence of regulatory $T$ cells with suppressive activity against autoreactive T-cell effectors.
\end{abstract}

Key words: Inflammation, Autoimmunity, Regulatory T cells, Tolerance, Neuroimmunology, Neuropeptide 


\section{Introduction: Needing immune tolerance control}

The successful elimination of most pathogens requires crosstalk between the innate and adaptive arms of the immune system. The innate immune system recognizes pathogenassociated molecular patterns through pattern-recognition receptors, which induce the release of pro-inflammatory cytokines, chemokines and free radicals, recruitment of inflammatory cells to the site of infection, and lysis of infected host cells by natural killer cells and cytotoxic T lymphocytes. A further damage arises from potential autoimmune responses occurring during the inflammatory response, in which the immune cells and molecules that respond to pathogen-derived antigens can also react to self-antigens. Therefore, in an inflammatory and autoimmune disease like rheumatoid arthritis, the initial stages involve multiple steps that can be divided into two main phases: early events associated with initiation and establishment of autoimmunity to joint components in peripheral lymphoid organs, and later events associated with the evolving immune and destructive inflammatory responses in the joint (Figure 1) (Firestein, 2003). Progression of the autoimmune response involves the development of self-reactive $T$ helper $1\left(T_{H} 1\right)$ cells, their entry into the joint, release of proinflammatory cytokines and chemokines, subsequent recruitment and activation of inflammatory cells (macrophages, neutrophils and mast cells) and synovial pannus formation. Production of inflammatory mediators, such as cytokines, matrixdegrading enzymes and free radicals by infiltrating cells and resident synovial cells (fibroblasts and osteoclasts) damages cartilage and bone. In addition, $\mathrm{T}_{\mathrm{H}}$ 1-mediated production of autoantibodies by B cells, which form immune complexes and activate complement and neutrophils, contribute to autoimmune pathology and disease propagation.

Therefore, safe induction of antigen-specific long-term tolerance is critical for the control of autoreactive $\mathrm{T}$ cells on autoimmune diseases. In addition, although critical for control of infection, the inflammatory process needs to be limited, since excessive responses result in severe inflammation and collateral tissue damage. In general, inflammatory responses are self-controlled by anti-inflammatory mediators secreted by host innate immune system during the ongoing process, and the ability to control an inflammatory state depends on the local 
balance between pro- and anti-inflammatory factors. Moreover, adaptive immune system also helps to maintain immune tolerance during infection-induced immunopathology (Mills, 2004). In addition to intrinsic control of lymphocytes, for example, central clonal deletion of self-reactive T cells in the thymus via apoptosis of immature self-reactive lymphocytes upon exposure to self-antigen or activation-induced cell death of mature effector cells, the generation of antigen-specific regulatory $T$ cells (Treg) plays a critical role in the induction of peripheral tolerance (Figure 1). For example, depletion of $\mathrm{CD} 4^{+} \mathrm{CD} 25^{+}$Treg cells produces autoimmune disease in otherwise normal animals, and their reconstitution prevents disease (Bluestone, 2005; Mills, 2004). In addition, Treg cells have been shown to be deficient in patients with rheumatoid arthritis, multiple sclerosis, type- 1 diabetes and other autoimmune diseases (Ehrenstein et al, 2004; Lindley et al., 2005; Viglietta et al, 2004). Moreover, numerous studies have demonstrated the therapeutic use of antigen-specific Treg cells in various models of autoimmune disorders (Bluestone, 2005).

From a therapeutic point of view, the fact that the appearance of exacerbated inflammatory and autoimmune diseases is consequence of an imbalance in pro-inflammatory factors versus anti-inflammatory cytokines, or in self-reactive $T_{H} 1$ cells versus Treg cells, becomes critical the identification of agents that restore self-tolerance by regulating both imbalanced inflammatory and autoreactive responses. One could think that endogenous factors might be produced by the immune cells during the autoimmune response in an attempt to maintain control. Numerous researchers have concentrated their efforts investigating traditional immunosuppressive cytokines, such as IL-10, IL-13 and TGF- $\beta 1$ (Wan and Flavell, 2006). However, others have focused their search in neuropeptides and hormones, classically considered as neuroendocrine mediators, but which are also produced by immune cells, especially under inflammatory conditions (Gonzalez-Rey et al., 2007a; Gonzalez-Rey and Delgado, 2007). Among them, cortistatin has recently emerged as a potential candidate to treat the unwanted immune responses that occur in inflammatory and autoimmune disorders. Here we examine the most recent developments regarding the effects of cortistatin on 
immune tolerance, and the effectiveness of using this neuropeptide in treating several autoimmune diseases.

\section{Cortistatin and immune tolerance}

Cortistatin is a recently discovered cyclic peptide that shows a high homology with somatostatin (de Lecea et al, 1996). Cortistatin shares many of the somatostatin pharmacological and functional properties, including the depression of neuronal activity and inhibition of cell proliferation (Spier and de Lecea, 2000). However, cortistatin also has many properties distinct from somatostatin such as slow-wave sleep induction and locomotor activity reduction (de Lecea et al, 1996; Spier and de Lecea, 2000). Cortistatin was initially identified in the central nervous system, essentially restricted to scattered neurons of the cerebral cortex and hippocampus (Spier and de Lecea, 2000). Contrary to the widespread distribution found for somatostatin, cortistatin is absent in a range of peripheral tissues. However, various human immune cells, including lymphocytes, monocytes, macrophages and dendritic cells (DCs) produce cortistatin, but not somatostatin, and its levels correlate with cell differentiation and activation state. This suggests that cortistatin might be a major endogenous regulatory factor in the immune system (Dalm, 2003; Dalm et al, 2003). In addition, cortistatin exerts its biological actions through various G-protein-coupled receptors (see below), that are expressed in various immune cells, such as T cells, macrophages, monocytes, DCs and neutrophils (Krantic, 2000; van der Lely et al., 2004).

Recent studies examining cortistatin have shown its relevance to health, proving a potential clinical significance in inflammatory and autoimmune diseases that upset the balance of body systems. Indeed, administration of cortistatin delays the onset, decreases the frequency and reduces the severity of various experimental models of sepsis (Gonzalez-Rey et al, 2006a), rheumatoid arthritis (Gonzalez-Rey et al, 2007b), and Crohn's disease (Gonzalez-Rey et al., 2006b). The therapeutic effect of cortistatin is associated with the reduction of the two main phases of these immune disorders. Cortistatin treatment impairs early events that are associated with the initiation and establishment of autoimmunity to self-tissue components, 
as well as later phases that are associated with the evolving immune and destructive inflammatory responses. Cortistatin reduces the development of self-reactive $T_{H} 1$ cells, their entry into the target organ, the release of pro-inflammatory cytokines (mainly TNF $\alpha$ and IFN $\gamma$ ) and chemokines, and the subsequent recruitment and activation of macrophages and neutrophils (Figure 1). This results in a decreased production of destructive inflammatory mediators (cytokines, nitric oxide, free radicals and matrix metalloproteinases) by infiltrating and resident (i.e., synoviocytes) inflammatory cells. In addition, the inhibition of the selfreactive $T_{H} 1$-cell response by cortistatin gives to a decreased titer of IgG2a autoantibodies, which activate complement and neutrophils and contribute to tissue destruction.

Numerous pieces of evidence demonstrate that the anti-inflammatory action of cortistatin is exerted at different levels of the innate immunity. Thus, cortistatin reduces the production of inflammatory cytokines (TNF $\alpha$, IL-12, IL-6, IL-18 and IL-1 $\beta$ ) and various chemokines (Rantes and MIP-2) by activated macrophages (Gonzalez-Rey et al, 2006a, 2006b). In addition, cortistatin downregulates the release of free radicals and nitric oxide in macrophages (Gonzalez-Rey et al, 2006a, 2006b). At the same, cortistatin stimulates the production of anti-inflammatory cytokines such as IL-10 (Gonzalez-Rey et al, 2006a). Finally, cortistatin decreases the co-stimulatory activity of antigen presenting cells (APCs) for antigen-specific T cells by downregulating the expression of the co-stimulatory molecules CD80 and CD86 (M.D. et al., unpublished data). Although the mechanisms involved in its suppressive effects on $T_{H} 1$-cell responses are not fully elucidated, it has been demonstrated that cortistatin regulates the $T_{H} 1 / T_{H} 2$ balance through various mechanisms involving both direct actions on differentiating $T$ cells and indirect regulation of APC functions (Figure 1) (Gonzalez-Rey et al., 2006b, 2007b). Interestingly, most of these immunomodulatory effects are shared by somatostatin (Krantic, 2000; Pinter et al., 2006), although comparatively, cortistatin was more efficient than somatostatin downregulating the inflammatory response, both in vitro and in vivo (Gonzalez et al., 2006a, 2006b, 2007b).

Finally, the generation of Treg cells has been recently found to play a major role in the beneficial effect of cortistatin in autoimmunity (Figure 1), and could explain the selective 
inhibition of $T_{H} 1$ immune responses once $T$ cells have completed differentiation into $T_{H} 1$ effector cells, as evidenced by the therapeutic effect of delayed administration of cortistatin in established arthritis (Gonzalez-Rey et al, 2007b). Cortistatin induces the peripheral expansion of new antigen-specific $\mathrm{CD} 4^{+} \mathrm{CD} 25^{+}$forkhead box P3 (FoxP3) ${ }^{+}$Treg cells, with suppressive activity on self-reactive T cells (Gonzalez-Rey et al., 2006b), by a mechanism dependent of the production of the immunosuppressive cytokines IL-10 and/or TGF $\tilde{\beta}$. It still remains unknown the type of Treg cells generated by cortistatin and the mechanism involved in such induction.

\section{Cortistatin is not somatostatin: a matter of receptor specificity}

Cortistatin shares 11 of the 14 residues with somatostatin, including the hydrophobic core of amino acids (FWKT) that is critical for binding to the five somatostatin receptors (SST1-5) and the two cysteines that render the peptide cyclic (Figure 2). Based in the strong structural similarity between both neuropeptides, corstistatin binds with high affinity to somatostatin receptors and shares several biological properties with somatostatin, such as decrease of cAMP levels in pituitary cells, cell proliferation inhibition and decrease of neuronal activity in hippocampal neurons (de Lecea et al, 1996). However, the lack of increased cortistatin expression in somatostatin deficient mice and the exclusive roles described for cortistatin on cortical electrical activity, locomotor behaviour and sleep (de Lecea et al, 1996; Spier and de Lecea, 2000; Ramirez et al, 2002), argue against a compensatory role of cortistatin, and raise the possibility that cortistatin exerts its differential activities through a receptor, or combination of receptors, that is essentially different from those that bind somatostatin. This potential capacity to activate different receptors and transduction pathways could partially explain why cortistatin downregulates inflammation and protect against autoimmune disorders more potently than somatostatin and its agonists (Gonzalez-Rey et al, 2006a, 2006b, 2007b). In this sense, it has been recently described that cortistatin, but not somatostatin, bind to the ghrelin receptor (GHSR) (Deghenghi et al, 2001), and signaling through GHSR and subsequent activation of the cAMP/PKA pathway has been associated 
with potent anti-inflammatory actions (Dixit et al., 2004; Gonzalez-Rey et al., 2006c, 2007b). Therefore, cortistatin might exert its anti-inflammatory effect through both SST and GHSR by signaling two different pathways: a cAMP-dependent pathway mediated through GHSR, and a cAMP-independent pathway mediated by SST (Figure 2). In agreement to this hypothesis, SST and GHSR antagonists have been found to partially reverse the anti-inflammatory effects of cortistatin (Gonzalez-Rey et al, 2006a, 2006b, 2007b). In addition, the participation of unidentified cortistatin-specific receptors cannot be ruled out. MrgX2 has been described as the first human cortistatin-selective receptor (Robas et al, 2003). However, although it is widely distributed in the peripheral tissues, $\operatorname{Mrg} X 2$ has not been detected in immune cells and does not signal through CAMP, arguing against the participation of this receptor in the cortistatin action on immune tolerance. Finally, an alterative possibility that need to be investigated is that, similar to other neuropeptide receptors (Poyner et al, 2002), certain receptor-activity-modifying proteins (RAMPs) could act in concert with one or more of the SST to form a receptor that preferentially binds cortistatin, where the RAMP subtype associated with SST determines the binding specificity for the ligand and the activity of the receptor.

\section{Concluding remarks}

The findings reviewed above indicate that cortistatin acts in a pleiotropic and in many cases redundant manner to regulate the balance between pro-inflammatory and anti-inflammatory factors, and between autoreactive $T_{H} 1$ cells and Treg cells (Figure 1). Based on these characteristics, cortistatin appears to represent an exciting prospect as a therapeutic agent for the treatment of immune diseases, such as rheumatoid arthritis, Crohn's disease and other immune diseases characterized by both inflammatory and autoimmune components. Induction of Treg cells by cortistatin has not only been crucial to a better understanding of the immunomodulatory action on cortistatin, but could also suppose the proposal of a new cellbased strategy for the treatment of immune disorders where tolerance restoration is needed. Considerable effort is recently focused on the use of antigen-specific Treg cells generated ex 
vivo to treat autoimmune diseases, transplantation and asthmatic disorders (Bluestone, 2005). The ability to translate important biological findings about Treg cells to the clinic has been limited by several issues, including the low frequency of these cells and the potential for pan immunosuppression. The potential solution for this problem should consist in expanding them and making them antigen-specific using selected antigens and peptides. However, although Treg cells replicate relatively efficiently in vivo, they are anergic and refractory to stimulation in vitro (Mills, 2004; Bluestone, 2005). Therefore, protocols that efficiently expand Treg populations in vitro while maintaining their immunoregulatory properties in vivo should be based in the conditions that allow their expansion in vivo, including T-cell receptor occupancy, crucial co-stimulatory signals and selective growth factors. Cortistatin could be one of these endogenous growth factors involved in the generation/expansion of Treg cells. Cortistatin shows therapeutic advantages versus agents directed only against one component of these diseases, where combinatory therapies have been proposed by other researchers. However, most studies describing the therapeutic potential of cortistatin have been carried out so far have been performed using animal models, and although valuable, these findings should be extended to human diseases with caution. Differences may be expected in terms of peptide dosage, and mainly in the expression of specific receptors by different immunocompetent cells. However, it is important to note that somatostatin has been extensively tested in human subjects, including patients with rheumatoid arthritis (Takeba et al, 1997; Paran et al, 2001; Weckbecker et al, 2003). Therefore, based in its somatostatinlike structure, cortistatin should be well tolerated in doses similar to those that are able to prevent immunological diseases in animals.

Despite these advantages, several obstacles stand between translating cortistatin basedtreatment into viable clinic therapies. Due to its natural somatostatin-like structural conformation, cortistatin should be very unstable and extremely sensitive to the peptidases present in most tissues. However, several strategies could be developed to increase cortistatin half-life such as by the modification and/or substitution of certain amino acids in 
the sequence increases the stability of the peptide, by the improvement of neuropeptide delivery to target tissues and cells while protecting it against degradation, or by neuropeptide gene delivery or its insertion into micelles or nanoparticles. Other strategies could combine cortistatin treatment with inhibitors of neutral endopeptidases to reduce the degradation of the peptide in the circulation. However, the principal approach of the pharmaceutical companies as a prerequisite for successful clinical applications is the development of metabolically stable analogues. Understanding of the structure/function relationship of cortistatin and its specific receptors, including receptor signaling, internalization and homo/heterodimerization, will be essential for the development of novel pharmacologic agents for the treatment of inflammatory/autoimmune disorders and opening up new applications for cortistatin derived treatments. In this sense, in an elegant experiment using the rationale that the amino acids contained within the cystein-cystein loop of cortistatin and somatostatin only differ by one amino acid whereas the extracyclic residues are distinct, Criado et al (1999) demonstrated that both the extracyclic N-terminal proline and the Cterminal lysine are necessary to elicit cortistatin's exclusive effects in the nervous system (Figure 2). It remains to investigate whether both extracyclic amino acids are involved in the differential effect of cortistatin in immune system. In any case, those structural-functional data could serve as a base to design of future specific and more potent cortistatin agonists. The generation of several somatostatin agonists by the pharmaceutical industry offered new therapeutic opportunities for the treatment of acromegaly and endocrine tumours (Weckbecker et al, 2003). However, compared to cortistatin, some SST agonists (i.e., octreotide) show much less effectiveness, if any, preventing inflammation and autoimmunity (Weckbecker et al, 2003; Gonzalez-Rey et al., 2006a, 2006b, 2007b). Further research will determine whether recently isolated nonpeptide GHSR agonists share some therapeutic actions with ghrelin and cortistatin.

Finally, it is significant that the organism responds to an exacerbated inflammatory response by increasing the peripheral production of endogenous anti-inflammatory neuropeptides, 
such as cortistatin, in an attempt to restore the immune homeostasis. In this sense, cortistatin could play a crucial role in the bidirectional communication that exists between the nervous system and the immune system, which is critical for the homeostasis of the body. Although the expression of cortistatin has been extensively described in the central nervous system, being especially circumscribed to cerebral cortex and hippocampus (de Lecea et al., 1996), no reports exist about the production of cortistatin by peripheral nervous system. This should be of especial relevance if we consider the important role that the somatostatin released by sensory nerves plays in the control of neurogenic inflammation and nociception (Pinter et al., 2006). Further studies will determine whether cortistatin could be also released from peptidergic sensory nerve endings in response to noxious and chemical stimuli and exert both anti-inflammatory and analgesic effects.

\section{Acknowledgements}

This work was supported by grants from the Spanish Ministry of Health (PI06/1291), Spanish Ministry of Education and Science (SAF2007-60101) and Junta de Andalucia.

\section{References}

Bluestone, J.A., 2005. Regulatory T-cell therapy: is it ready for the clinic? Nat. Rev. Immunol. 5, 343-349.

Criado, J.R., Li, H., Jiang, X., Spina, M., Huitron-Resendiz, S., Liapakis, G., Calbet, M., Siehler, S., Henriksen, S.J., Koob, G., Hoyer, D., Sutcliffe, J.G., Goodman, M., de Lecea, L., 1999. Structural and compositional determinants of cortistatin activity. J. Neurosci. Res. 56, $611-619$.

Dalm, V.A., 2003. Expression of somatostatin, cortistatin, and somatostatin receptors in human monocytes, macrophages, and dendritic cells. Am. J. Physiol. Endocrinol. Metab. 285, E344-E353. 
Dalm, V.A., van Hagen, P.M., van Koetsveld, P.M., Langerak, A.W., van der Lely, A.J., Lamberts, S.W., Hofland, L.J., 2003. Cortistatin rather than somatostatin as a potential endogenous ligand for somatostatin receptors in the human immune system. J. Clin. Endocrinol. Metab. 88, 270-276.

de Lecea, L., Criado, J.R., Prospero-Garcia, O., Gautvik, K.M., Schweitzer, P., Danielson, P.E., Dunlop, C.L., Siggins, G.R., Henriksen, S.J., Sutcliffe, J.G., 1996. A cortical neuropeptide with neuronal depressant and sleep-modulating properties. Nature 381, 242245.

Deghenghi, R., Papotti, M., Ghigo, E., Muccioli, G., 2001. Cortistatin, but not somatostatin, binds to growth hormone secretagogue (GHS) receptors of human pituitary gland. J. Endocrinol. Invest. 24, RC1-RC3.

Dixit, V.D., Schaffer, E.M., Pyle, R.S., Collins, G.D., Sakthivel, S.K., Palaniappan, R., Lillard, J.W. Jr., Taub, D.D., 2004. Ghrelin inhibits leptin- and activation-induced proinflammatory cytokine expression by human monocytes and T cells. J. Clin. Invest. 114, $57-66$.

Ehrenstein, M.R., Evans, J.G., Singh, A., Moore, S., Warnes, G., Isenberg, D.A., Mauri, C., 2004. Compromised function of regulatory T cells in rheumatoid arthritis and reversal by anti-TNF $\alpha$ therapy. J. Exp. Med. 200, 277-285.

Firestein, G.S., 2003. Evolving concepts of rheumatoid arthritis. Nature 423, 356-361.

Gonzalez-Rey, E., Chorny, A., Robledo, G., Delgado, M., 2006a. Cortistatin, a new antiinflammatory peptide with therapeutic action in lethal endotoxemia. J. Exp. Med. 203, 463471.

Gonzalez-Rey, E., Varela, N., Sheibanie, A.F., Chorny, A., Ganea, D., Delgado, M., 2006b. Cortistatin, a new anti-inflammatory peptide with therapeutic action in inflammatory bowel disease. Proc. Natl. Acad. Sci. USA 103, 4228-4233.

Gonzalez-Rey, E., Chorny, A., Delgado, M., 2006c. Therapeutic action of ghrelin in an experimental model of colitis. Gastroenterology 130, 1707-1720. 
Gonzalez-Rey, E., Chorny, A., Delgado, M., 2007a. Regulation of immune tolerance by anti-inflammatory neuropeptides. Nat. Rev. Immunol. 7, 52-63.

Gonzalez-Rey, E., Chorny, A., Del Moral, R.G., Varela, N., Delgado, M., 2007b. Therapeutic effect of cortistatin on experimental arthritis by downregulating inflammatory and Th1 responses. Ann. Rheum. Dis. 66, 582-588.

Gonzalez-Rey. E., Delgado, M., 2007. Anti-inflammatory neuropeptide receptors: new therapeutic targets for immune disorders? Trends. Pharmacol. Sci. (in press).

Krantic, S., 2000. Peptides as regulators of the immune system: emphasis on somatostatin. Peptides 21, 1941-1964.

Lindley, S., Dayan, C.M., Bishop, A., Roep, B.O., Peakman, M., Tree, T.I., 2005. Defective suppressor function in $\mathrm{CD} 4^{+} \mathrm{CD} 25^{+}$T-cells from patients with type 1 diabetes. Diabetes 54, 92-99.

Mills, K.H.G., 2004. Regulatory T cells: friend or foe $n$ immunity to infection? Nat Rev Immunol 4, 841-855.

Paran, D., Elkayam, O., Mayo, A., Paran, H., Amit, M., Yaron, M., Caspi, D., 2001. A pilot study of a long acting somatostatin analogue for the treatment of refractory rheumatoid arthritis. Ann. Rheum. Dis. 60, 888-891.

Pinter, E., Helyes, Z., Szolcsanyi, J., 2006. Inhibitory effect of somatostatin on inflammation and nociception. Pharm. Ther. 112, 440-456.

Poyner, D.R., Sexton, P.M., Marshall, I., Smith, D.M., Quirion, R., Born, W., Muff, R., Fischer, J.A., Foord, S.M., 2002. International Union of Pharmacology. XXXII. The mammalian calcitonin gene-related peptides, adrenomedullin, amylin, and calcitonin receptors. Pharmacol. Rev. 54, 233-246.

Ramirez, J.L., Mouchantaf, R., Kumar, U., Otero Corchon, V., Rubinstein, M., Low, M.J., Patel, Y.C., 2002. Brain somatostatin receptors are up-regulated in somatostatin-deficient mice. Mol. Endocrinol. 16, 1951-1963.

Robas, N., Mead, E., Fidock, M., 2003. MrgX2 is a high potency cortistatin receptor expressed in dorsal root ganglion. J. Biol. Chem. 278, 44400-44404. 
Spier, A.D., de Lecea, L., 2000. Cortistatin: a member of the somatostatin neuropeptide family with distinct physiological functions. Brain Res. Rev. 33, 228-241.

Takeba, Y., Suzuki, N., Takeno, M., Asai, T., Tsuboi, S., Hoshino, T., Sakane, T., 1997. Modulation of synovial cell function by somatostatin in patients with rheumatoid arthritis. Arthritis Rheum. 40, 2128-2138.

van der Lely, A.J., Tschop, M., Heiman, M.L., Ghigo, E., 2004. Biological, physiological, pathophysiological, and pharmacological aspects of ghrelin. Endocr. Rev. 25, 426-457.

Viglietta, V., Baecher-Allan, C., Weiner, H.L., Hafler, D.A., 2004. Loss of functional suppression by $\mathrm{CD} 4^{+} \mathrm{CD} 25^{+}$regulatory T cells in patients with multiple sclerosis. J. Exp. Med. 199, 971-979.

Wan, Y.Y., Favell, R.A., 2006. The roles for cytokines in the generation and maintenance of regulatory T cells. Immunol. Rev. 212, 114-130.

Weckbecker, G., Lewis, I., Albert, R., Schmid, H.A., Hoyer, D., Burns, C., 2003. Opportunities in somatostatin research: biological, chemical and therapeutic aspects. Nat. Rev. Drug Disc. 2, 999-1017. 


\section{Figure Legends}

Figure 1.- Cortistatin restores tolerance in autoimmune disorders at multiple levels. Loss of immune tolerance results in the onset of autoimmune disorders. This figure illustrates one scenario depicting the stepwise progression of the development of rheumatoid arthritis. The initial stages of the disease take place in peripheral lymphoid organs, are associated with initiation and establishment of autoimmunity to joint components, and involve the development of self-reactive $T$ helper $1\left(T_{H} 1\right)$ cells by dendritic cells (DCs) presenting selfantigens. In addition, $T_{H} 1$ cells induce the production of IgG2 autoantibodies by autoreactive $\mathrm{B}$ cells and the deposition of immune complexes in the joint. Progression of the autoimmune response involves the entry of autoreactive $T_{H} 1$ cells into the joint, release of proinflammatory cytokines (tumour-necrosis factor- $\alpha$ (TNF $\alpha$ ) and interferon- $\gamma$ (IFN $\gamma$ )) and chemokines and subsequent recruitment and activation of inflammatory cells (macrophages and neutrophils). In addition, autoantibodies activate complement, neutrophils and mast cells. Later events are associated with the evolving immune and destructive inflammatory responses. Inflammatory mediators, such as cytokines, nitric oxide (NO), free radicals and metalloproteinases (MMP), which are produced by infiltrating cells and resident synovial cells have a crucial role in cartilage and bone destruction. Naturally occurring $\mathrm{CD} 4^{+} \mathrm{CD} 25^{+} \mathrm{T}$ regulatory $\left(T_{\text {Reg }}\right)$ cells or induced regulatory $T$ cells are key players in maintaining tolerance by their suppression of self-reactive $T_{H} 1$ cells. Imbalance of regulatory $T$ cells versus $T_{H} 1$ cells, or of anti-inflammatory cytokines versus proinflammatory factors, are the cause of autoimmune disorders. Cortistatin (CST) induces immune tolerance and inhibits the autoimmune response through different mechanisms. A) Cortistatin decreases $T_{H}$ 1-cell functions through direct actions on differentiating $\mathrm{T}$ cells, or indirectly by regulating dendritic cell (DC) functions. As a consequence, the inflammatory and autoimmune responses are impaired because the infiltration/activation of neutrophils and macrophages and deposition of immune complexes are avoided. B) Cortistatin inhibits the production of inflammatory cytokines, chemokines and free radicals by macrophages and synoviocytes, avoiding the inflammatory response and its cytotoxic effect against joint components. C) Cortistatin 
induces the new generation of peripheral Treg cells that suppress activation of autoreactive $T$ cells through a mechanism that involves production of interleukin-10 (IL-10) and transforming growth factor- $\beta$ (TGF $\beta$ ). Arrows indicate a stimulatory effect. Back-crossed lines indicate an inhibitory effect.

Figure 2.- The differential effect of somatostatin and cortistatin in immune system is a matter of receptor specificity. Amino acid sequences of native murine somatostatin (SS14) and cortistatin (CST-14) are shown, where the boxes delimitate the amino acids essential for binding with the five cloned somatostatin receptors (SST1-5), and the amino acids that confer exclusive cortistatin-like functions are highlighted. Somatostatin binds only to the five SSTs and signals by decreasing cAMP levels. Cortistatin, in addition to its binding to SST1-5, signals through the ghrelin receptor (GHSR) and activates the cAMP-protein kinase A pathway. A still unidentified receptor specific for cortistatin could be also involved in its antiinflammatory action. 


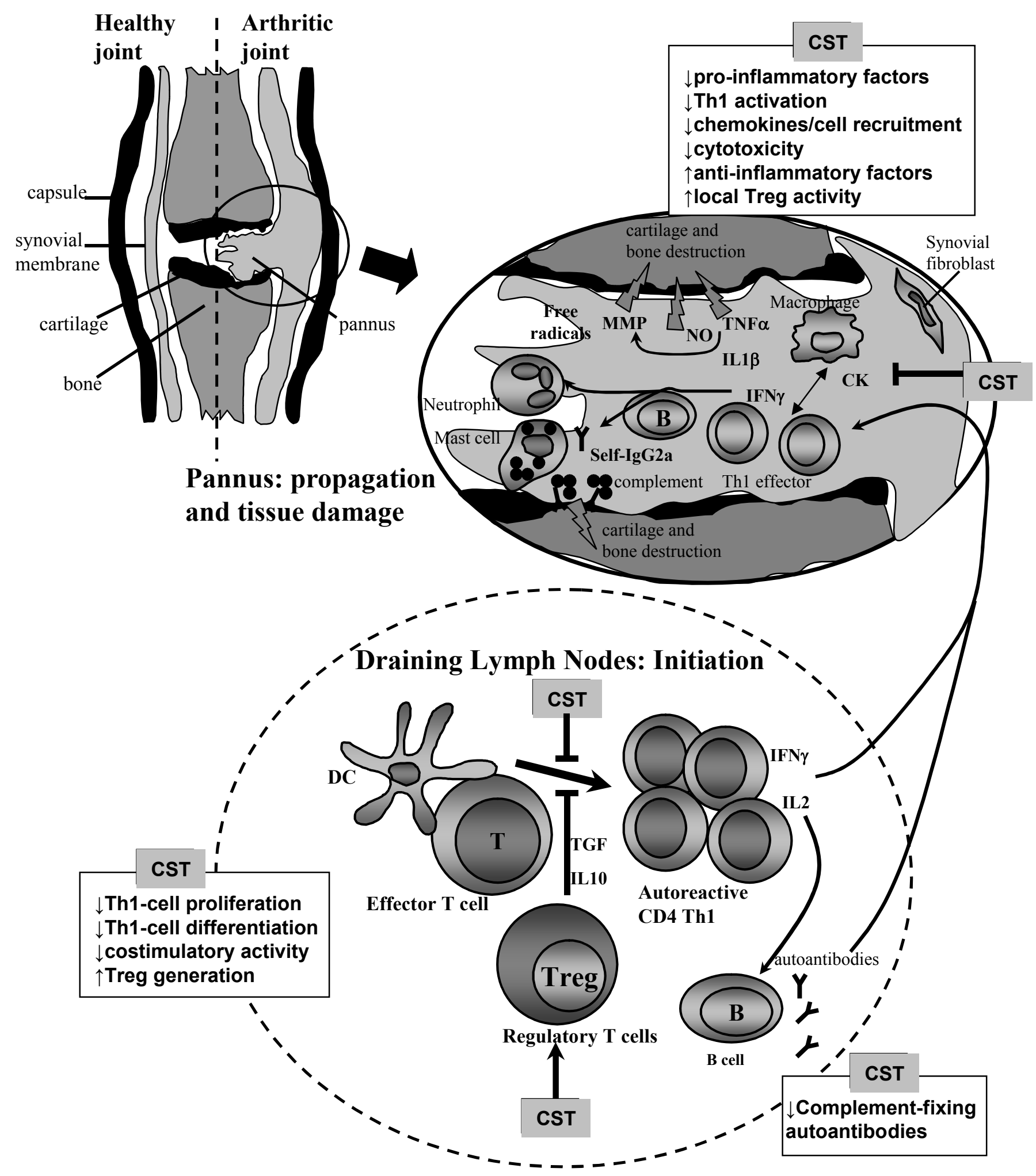

Figure 1 

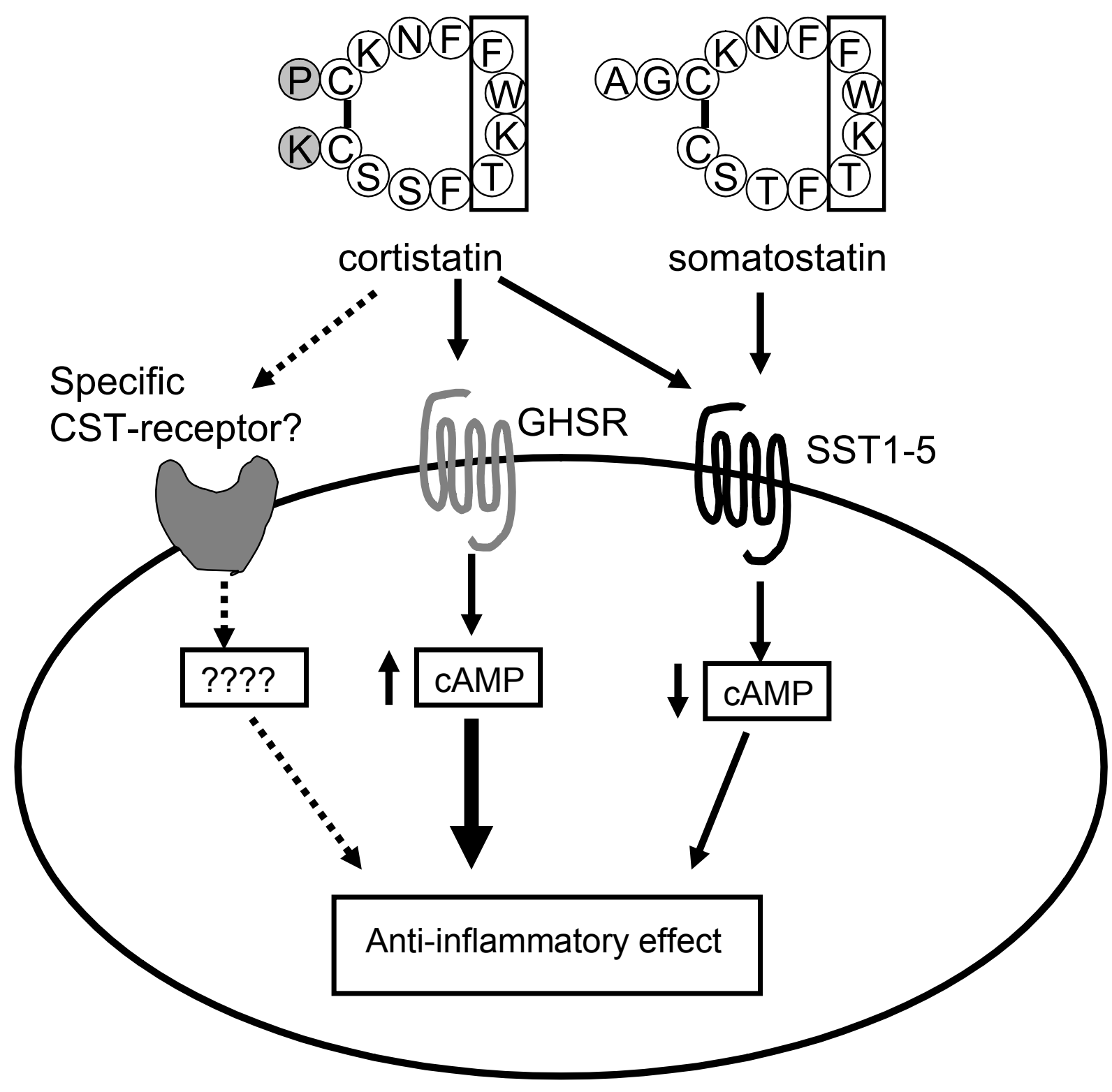

Figure 2 